\title{
A experiência da queimadura na perspectiva do paciente
}

\author{
BURN EXPERIENCES FROM THE PATIENT'S PERSPECTIVE
}

\section{LA EXPERIENCIA DE QUEMADURA EN LA PERSPECTIVA DEL PACIENTE}

\author{
Viviane Dias da Silva Carlucci' ${ }^{1}$, Lídia Aparecida Rossi², Ana Maria F T Ficher ${ }^{3}$, \\ Enéas Ferreira ${ }^{4}$, Emília Campos de Carvalho ${ }^{5}$
}

\section{RESUMO}

Este estudo teve como objetivos identificar as situações vivenciadas por pacientes queimados, percebidas por eles durante a internação como significantes, e identificar os sentimentos e conseqüências decorrentes das situações relatadas. A Técnica do Incidente Crítico foi utilizada para coletar dados com base nos relatos de fatos observados e vivenciados previamente pelos pacientes. Trinta pacientes foram submetidos à entrevista semi-estruturada. As situações identificadas como significantes foram categorizadas da seguinte forma: sentir dor e ter que se submeter a procedimentos; viver uma experiência nova, receber apoio da família e da equipe e conhecer a situação de outras pessoas queimadas. Os sentimentos e comportamentos relatados foram: ansiedade e medo, sofrimento e conforto ao ver outras pessoas em piores condições. A vivência dessa experiência trouxe como consequiências: mudanças de valores, no estilo de vida, no papel social e na saúde.

\section{DESCRITORES}

Queimaduras/reabilitação.

Cuidados de enfermagem.

Hospitalização.

Emoções.

\section{ABSTRACT}

This study was aimed at identifying situations experienced by burned patients which they perceived as significant during hospitalization, as well as identifying the feelings and consequences that resulted from the reported situations. The Critical Incident Technique was used for data collection, based on descriptions of facts which patients had previously observed and experienced as referred to by their memories. Thirty patients were submitted to semi-structured interviews. The situations identified as significant were categorized as follows: feeling pain and having to subject themselves to procedures; having a new experience, receiving family and team support or not; and knowing the situation of other burned persons. The feelings and behaviors that were mentioned were anxiety and fear, and suffering and comfort when seeing others whose conditions are worse. From the perspective of patients, the consequences of going through this experience were changes in values, lifestyle, social role and health.

\section{KEY WORDS}

Burns/rehabilitation.

Nursing care.

Hospitalization.

Emotions.

\section{RESUMEN}

En este estudio se tuvo como objetivos identificar las situaciones vivenciadas por pacientes quemados, percibidas por ellos durante el internamiento como sentimientos y consecuencias derivadas de las situaciones relatadas. La Técnica del Incidente Crítico fue utilizada para recolectar datos a partir de relatos de hechos observados y vivenciados previamente por los pacientes. Treinta pacientes fueron sometidos a una entrevista semi estructurada. Las situaciones identificadas como significantes se categorizaron de la siguiente forma: sentir dolor y tener que someterse a procedimientos; vivir una experiencia nueva, recibir apoyo de la familia y del equipo y conocer la situación de otras personas quemadas. Los sentimientos y comportamientos relatados fueron: ansiedad y miedo, sufrimiento y confort al ver a otras personas en peores condiciones. La vivencia de esa experiencia trajo como consecuencias: cambio de valores, en el estilo de vida, en el papel social y en la salud. significantes e identificar los

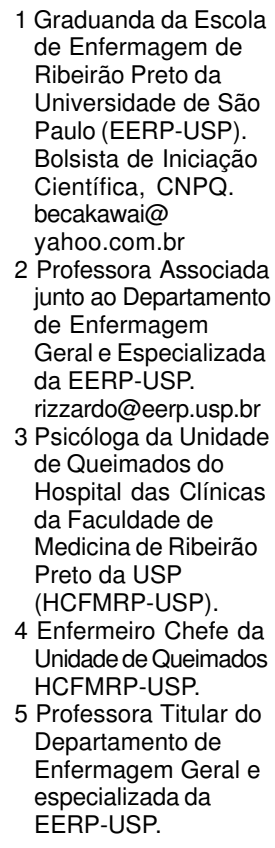

\section{DESCRIPTORES}

Quemaduras/reabilitación.

Atención de enfermería.

Hospitalización.

Emociones. 


\section{INTRODUÇÃO}

Um trauma térmico, independentemente de sua extensão, é uma agressão que pode causar danos físicos e psicológicos ao paciente. Para o paciente que sofreu queimaduras e necessita de internação hospitalar, essa é uma fase complicada, pois ele será atingido por uma variedade de estressores físicos tais como acidose, perda de fluidos, alterações no equilíbrio endócrino, potencial para infecção, dor, além dos estressores psicológicos decorrentes de situações como separação da família, afastamento do trabalho, mudanças corporais, despersonalização, dependência de cuidados, perda da autonomia e tensão constante.

No momento em que são prestados os primeiros cuidados ao paciente, os profissionais de saúde preocupam-se em reanimar o estado fisiológico a fim de estabelecer um quadro estável para que, posteriormente, ele possa ser avaliado considerando-se também o estado psicológico. Durante o período de hospitalização, a pessoa que sofre uma queimadura passa a perceber a extensão de seu problema e a pensar como poderão ficar as cicatrizes, se haverá seqüelas mais graves que possam comprometer, de alguma forma, a estrutura ou função do corpo, limitando atividades importantes como as atividades de vida diária, o autocuidado, a higiene corporal e o trabalho.

O foco principal de interesse deste estudo foi a identificação, a partir da perspectiva de pacientes queimados, das experiências vivenciadas por eles, percebidas durante a internação como significantes.

Considera-se que, ao sofrer uma queimadura, o paciente passará por três fases distintas que se relacionam tanto com a recuperação física quanto com a psicológica. A primeira fase, chamada por muitos autores de estágio crítico ${ }^{(1)}$, de ressuscitação ou de estabilização ${ }^{(2)}$, corresponde às primeiras 72 horas após a ocorrência do acidente e se caracteriza pela instabilidade do paciente ${ }^{(1)}$. Após a estabilização, o paciente passará por uma fase aguda de reabilitação que envolve a realização de procedimentos bastante dolorosos e que, freqüentemente, começam a gerar expectativas, em relação aos seus resultados. Esses procedimentos ocorrem em um momento de maior consciência de impacto físico e psicológico do trauma ${ }^{(1)}$. Finalmente, a terceira fase, que tem sido chamada de reabilitação de longa duração, começa quando o paciente está para ter alta hospitalar ${ }^{(2)}$.

Após uma queimadura, o paciente e seus familiares passarão a enfrentar uma situação de desequilíbrio caracterizada, na fase de ressuscitação, pela ameaça de morte e expressão de medo da morte. Posteriormente, na fase seguinte, a dor consistirá o grande problema a ser enfrentado pelo paciente. Na fase de reabilitação, a preocupação do pacien- te será com a vida fora do hospital, considerando-se as mudanças corporais que poderá apresentar ${ }^{(3)}$.

Em um relato de casos, em que foram enfocados os problemas emocionais que a pessoa queimada apresenta, observou-se que, na fase aguda, o paciente que sofreu queimaduras apresenta também um choque emocional, decorrente de fatores emocionais e orgânicos, que se manifesta por meio de sintomas característicos como insônia, labilidade emocional, estado de alarme e pesadelos com o traumatismo ${ }^{(4)}$. Nessa fase, muitos pacientes não reconhecem a gravidade de seu caso. $\mathrm{O}$ medo da mutilação poderá aparecer na fase seguinte ${ }^{(4)}$.

Na revisão da literatura, encontramos estudos que relacionam a intensidade dos sentimentos apresentados por pacientes queimados à extensão do trauma ${ }^{(1,5)}$, à troca de $\operatorname{curativos}^{(6)}$, à outros procedimentos médicos ${ }^{(7)}$, à ocorrência de sintomas de estresse e aos distúrbios do sono ${ }^{(8)}$. Observou-se ainda, na literatura, que os sintomas de dor e ansiedade podem variar em função do nível e da extensão da queimadura $^{(1,5)}$. A presença desses problemas pode estar relacionada às relações familiares ou matrimoniais problemáticas ${ }^{(1)}$. A ansiedade associada à dor tem sido focalizada na literatura como um dos problemas que afetam o paciente que sofreu queimaduras durante o período de hospitalização ${ }^{(9-11)}$. As manifestações desses dois problemas estão associadas às trocas diárias de curativos e à realização de outros procedimentos ${ }^{(11)}$.

Outros autores enfocaram ainda, o significado das reações emocionais atribuídas por vítimas de queimaduras. Nessa perspectiva, realizou-se uma revisão de literatura sobre as reações emocionais que uma pessoa queimada sofre após a ruptura da pele em grande extensão, enfocando não somente o significado da função da pele enquanto uma proteção física, mas também o seu papel protetor no que se refere aos aspectos emocionais. $\mathrm{O}$ autor acredita que a perda da integridade da pele pode acarretar transtornos como confusão e problemas com a identidade pessoal ${ }^{(12)}$.

Embora muitos estudos apontem as diferentes reações apresentadas pelos pacientes durante o processo de hospitalização ${ }^{(1,5)}$, não encontramos estudos que abordassem as perspectivas dos pacientes sobre fatos ocorridos durante o período de internação, considerados como relevantes para eles, exceto um estudo ${ }^{(13)}$ que teve como objetivo conhecer o significado da vivência de estar queimado, durante o período de internação e discutir a relação de ajuda que a enfermeira de saúde mental poderia estabelecer com esse paciente. Nesse estudo, os participantes também reportaram como fato importante a dor durante a realização dos procedimentos de banho e curativo. 
Assim, em decorrência das diferentes reações emocionais que os pacientes, freqüentemente, apresentam nos diferentes momentos de internação, entendemos que é importante conhecer as perspectivas apresentadas por eles em relação aos fatos vivenciados nesse período e que foram considerados como significantes por essas pessoas. Portanto, os objetivos deste estudo foram: identificar as situações vivenciadas por pacientes queimados durante a internação, percebidas como significantes e os sentimentos e conseqüências decorrentes das situações relatadas.

\section{MÉTODO}

O presente estudo caracteriza-se como descritivo do tipo retrospectivo e foi realizado no ambulatório da Unidade de Queimados do Hospital das Clínicas da Faculdade de Medicina de Ribeirão Preto, após aprovação do Comitê de Ética e Pesquisa da Instituição. Essa Unidade possui oito leitos e atende adultos e crianças em regime de internação e ambulatorial. Pacientes maiores de 12 anos, de ambos os sexos, que estiveram internados na Unidade de Queimados quando sofreram o acidente e que concordaram em participar da pesquisa foram submetidos a uma entrevista individual e semi-estruturada. Foram entrevistados 31 pacientes que compareceram ao ambulatório da Unidade para seguimento no período de 6 de setembro de 2002 a 20 de agosto de 2003 . Um paciente foi excluído pois, durante a entrevista, suas respostas foram influenciadas pelo familiar que o estava acompanhando.

Na condução dos procedimentos metodológicos deste estudo, elegemos a Técnica de Incidentes Críticos, pois essa técnica permite analisar fatos observados e vivenciados previamente, que são reportados pela memória. Essa técnica tem sido empregada por diferentes autores, em diferentes situações que envolvem a prática de enfermagem como o transporte de pacientes ${ }^{(14)}$, os comportamentos da equipe de enfermagem ${ }^{(15)}$ e de pacientes ${ }^{(16)}$. Essa técnica permite conhecer as perspectivas dos pacientes sobre como situações significativas aconteceram e, assim, possibilita aos enfermeiros compreenderem muitos dos comportamentos que os pacientes frequentemente exibem e que, a princípio, podem parecer contraproducentes para o cuidado.

\section{A Técnica do Incidente Crítico consiste em}

um conjunto de procedimentos para coleta de observações diretas do comportamento humano, de modo a facilitar sua utilização potencial na solução de problemas práticos e no desenvolvimento de princípios psicológicos ${ }^{(17)}$.

Um incidente crítico é qualquer atividade humana observável, suficientemente completa em si mesma, para permitir inferências e previsões a respeito da pessoa que executa $\mathrm{o}$ ato ${ }^{(17)}$.
Após a assinatura do Termo de Consentimento Livre e Esclarecido, os pacientes foram entrevistados e a entrevista foi registrada por meio de um gravador. Para pacientes menores de 21 anos, o termo de consentimento foi solicitado a ambos: paciente e responsável. A entrevista foi composta por cinco questões, sendo que a primeira abordava aspectos gerais sobre o paciente e as outras estavam relacionadas aos incidentes críticos que pretendíamos identificar: O que mais te marcou durante a internação? ou Quais as situações vivenciadas que foram mais marcantes para você? Por quê? O que você fazia elou o que sentia durante essas situações que foram marcantes para você? Essas situações tiveram algumas conseqüências para você? Você acha que o que vivenciou durante a internação poderia ter acontecido de forma diferente? Como você considera que os profissionais de saúde poderiam ajudar o paciente a enfrentar essas situações durante a internação?

Os incidentes foram analisados de acordo com três aspectos: situações e momento em que eles ocorreram, comportamentos e sentimentos relatados pelos pacientes e suas consequiências. As situações foram definidas como incidentes críticos quando foram consideradas como significantes pelo paciente durante o processo de internação para tratamento da queimadura.

A análise dos dados foi realizada por três dos autores separadamente (uma enfermeira, uma acadêmica de enfermagem e uma psicóloga em quatro estágios: 1) leitura e identificação dos incidentes críticos, por meio de análise de conteúdo dos relatos; 2) identificação das situações reportadas pelos pacientes, buscando separar sentimentos, comportamentos e conseqüências decorrentes da experiência relatada; 3) agrupamento dos relatos semelhantes e 4) categorização e classificação final das situações, comportamentos, sentimentos e consequiências ${ }^{(15)}$. É importante ressaltar que os três autores deste estudo, que realizaram esse procedimento, participaram de uma reunião que antecedeu a análise, para que tentassem previamente padronizar o entendimento sobre cada uma das categorias: situação, comportamento, sentimentos e conseqüências. Para realização desse procedimento, foram utilizadas informações de três entrevistas selecionadas aleatoriamente. Após a análise dos dados das três entrevistas, a categorização realizada por cada um desses autores foi comparada, buscando-se atingir um consenso.

Nessa fase, observaram-se divergências entre a compreensão do significado das categorias comportamentos e sentimentos. Apesar das diferenças nos níveis de formação e também no tipo de profissão entre as pessoas que realizaram esse procedimento, as divergências, apresentadas a princípio, foram em pequeno número. Essas divergências foram sanadas discutindo-se os diferentes exemplos de categorias (situações, sentimentos, comportamento e consequiências) observadas nas três entrevistas. Uma vez obtido um consenso sobre o significado de cada uma das categorias 
citadas anteriormente, procedeu-se a análise de todas as entrevistas por todos os autores de forma individual. Posteriormente, foi realizada uma comparação entre as análises realizadas. Nesse processo, não foram observadas divergências relacionados aos significados das categorias.

\section{RESULTADOS}

Participaram do estudo 30 pacientes que sofreram queimaduras. Desses pacientes, 19 eram do sexo masculino e 11, feminino. Em relação ao tipo de acidente, 11 pacientes sofreram queimaduras em acidentes domésticos, 10 em acidentes de trabalho, 4 em acidentes automobilísticos e 5 resultaram de auto-agressão. Do total de participantes, segundo registro no prontuário, 2 pacientes apresentavam quadro psicótico e 3, quadro depressivo na ocasião do acidente; entretanto, no momento da entrevista, apresentavam-se em condições de responder às perguntas.

Assim, os discursos de 30 pacientes foram considerados para análise. As situações mais relevantes relatadas pelos pacientes foram agrupadas em: ter que se submeter a procedimentos e sentir dor; receber ou não o apoio da família e da equipe; viver uma nova experiência; conhecer a situação de outras pessoas queimadas (Quadro 1).

Quadro 1 - Situações consideradas pelos pacientes como significantes, segundo a categoria

\begin{tabular}{|lc|}
\hline Situações & Resultado \\
\hline Ter que se submeter a procedimentos e sentir & 26 \\
dor & 20 \\
Receber ou não o apoio da família e da equipe & 8 \\
Viver uma experiência nova & 6 \\
Conhecer a situação de outras pessoas & \\
queimadas & \\
\hline
\end{tabular}

Observa-se, no Quadro 1, que a experiência de sentir dor foi considerada por 26 participantes como uma situação significante. Nesse caso, foram consideradas as situações relacionadas à realização de procedimentos como banho, curativo e cirurgia que causavam dor, além da própria dor da queimadura. A seguir são apresentados alguns exemplos de relatos de pacientes relacionados à manifestação de dor:

Paciente $1^{(a)}$ : Ah, depois que eu saí da cirurgia, umas oito horas depois, eu fiquei apavorado, sabe, doía muito.

Paciente 4: Ah, é um trauma que a gente não esquece, um tratamento muito dolorido.

O apoio da família e da equipe foi considerado importante por 20 pacientes. É importante destacar que eles citaram que o apoio recebido foi muito importante e que outros ressaltaram a falta de apoio da equipe e da família como um fator que dificultou a vivência dessa experiência.

(a) Os pacientes foram identificados por números
Paciente 7: O que me marcou bastante, foi a ajuda psicológica assim, do próprio pessoal, dos parentes, dos amigos, que não me deixaram um minuto, não teve um dia que eu não tive duas visitas, todo dia eu tive duas visitas, então isso me marcou bastante, eu cheguei a ter oito, dez visitas por dia. Então isso ai me marcou muito, o amor de todo mundo que chegava me dava força. Eu cheguei num estado realmente que parece que eu estava desanimando, mas o pessoal me dava força, graças a Deus venci.

Paciente 9: (...) alguns parentes me visitavam, não com muita freqüência, né, a gente fica meio só, né, meio solitário tal.

Os participantes relataram, ainda como significante a vivência de estar queimado como algo novo, uma situação nova e nunca esperada.

Paciente 16: (...) tudo era uma coisa nova, tudo era um momento de susto, um susto muito grande, eu entrando no hospital, nunca tinha entrado, meu corpo todo daquele jeito queimado, tudo era diferente, então.

Paciente 23: (...) eu nunca tinha passado por uma experiência assim, sabe. Com pessoas assim com dificuldades igual a eu, uma experiência que foi muito forte.

A experiência de conhecer a situação de outras pessoas queimadas foi considerada por 6 participantes como uma situação significante, principalmente quando observavam crianças queimadas e pessoas que, na percepção deles, estavam em condições piores.

Paciente 11: Olha, eu fiquei dois meses aqui, deu para marcar bastante coisa, principalmente diversos casos que chegavam aqui, tipo de queimado, como se queimou, quanta história sabe, que eu ouvia, então eu só com os dois dedos queimados, eu nunca pensava o que eu ia viver o que eu vivi aqui, o que eu vi aqui.

Paciente 22: (...) ó o que mais doía era ver as crianças, os adultos a gente sabia que tinha dor, mais dá para agüentar, mas as crianças, era muito difícil ver elas com dor.

O Quadro 2 apresenta as categorias de sentimentos e comportamentos consideradas pelos pacientes como significantes.

Quadro 2 - Sentimentos e Comportamentos considerados pelos pacientes como significantes, segundo a categoria

\begin{tabular}{|lc|}
\hline Sentimentos/Comportamentos & Resultado \\
\hline Sofrimento & 20 \\
Ansiedade e medo & 14 \\
Sentimento de conformismo ao ver & 3 \\
outras pessoas em piores condições & \\
\hline
\end{tabular}

Em relação ao sofrimento ou a suas manifestações, 20 dos 30 participantes relataram os seguintes sentimentos e comportamentos: choro, tristeza, revolta, remorso, soli- 
dão e saudade. Apenas um participante relatou sentir-se revoltado.

Paciente 7 : Eu senti uma tristeza sabe? Porque eu sempre fui uma pessoa independente, sempre tentei fazer os meus negócios sozinho tá, e quando eu me reparei desse jeito, queimado, com as peles saindo, precisando de ajuda para comer, para fazer as necessidades, para tudo, para deitar (...).

Paciente 3: Eu chorava, pois não dava para fazer mais nada.

A ansiedade e o medo foram os sentimentos considerados como significantes por 14 participantes. Nessa categoria, foram agrupados os relatos de desespero, vontade de ir embora e nervosismo.

Paciente 1: Ah foi os primeiros dias, fiquei com muito medo, sabe...

Paciente 5: (...) eu fiquei com medo de perder o pé sabe, então foi que eu fiquei muito apavorado, os médicos correram, fizeram enxerto no meu pé aqui.

Relataram sentimento de conformismo ao ver outras pessoas em piores condições 3 participantes

Paciente 12 : (...) mas mesmo assim eu agradeço a Deus porque era para ter morrido, pelo menos estou com a minha filha, aí eu vejo pessoas que estão bem pior do que eu, e eu conformo com isso.

Paciente 18: Bom, ao mesmo tempo que eu colocava o meu problema na frente se julgando o pior, sei lá, via problemas piores que o meu, ao mesmo tempo que isso me relaxava, sei lá, passava.

O Quadro 3 apresenta as categorias de conseqüências relatadas pelos pacientes como significantes.

Quadro 3 - Conseqüências relatadas pelos pacientes como significantes, segundo a categoria

\begin{tabular}{|lc|}
\hline Conseqüências & Resultado \\
\hline Mudanças no estado de saúde & 14 \\
Mudanças de valores & 7 \\
Mudanças no estilo de vida & 6 \\
Mudanças no papel social e nas relações & 3 \\
interpessoais & 10 \\
Sem identificação de conseqüências & \\
\hline
\end{tabular}

Observa-se, no Quadro 3, que as conseqüências de terem passado por situações consideradas, pelos pacientes queimados, como significantes foram todas relatadas como mudanças: na saúde, de valores, no estilo de vida e no papel social. Não identificaram conseqüências 10 participantes.

A mudança na saúde, enquanto uma conseqüência das situações reportadas, foi apontada por 14 participantes. Nessa categoria, foram consideradas as descrições de: limitações físicas, de não poder tomar sol e alterações emocionais. Dentre as mudanças na saúde relatadas pelos pacientes, é importante destacar as descrições de alterações emocionais como decorrentes das situações vivenciadas, por 4 pacientes, como depressão. Além da depressão, 1 participante relatou a identificação de diagnósticos de Hipertensão Arterial e Diabetes Mellitus, considerados por ele, como um aspecto positivo da internação, pois não sabia que era portador de tais patologias. Outro participante identificou o diagnóstico de Sífilis como uma conseqüência da queimadura, embora esse problema não estivesse associado ao trauma.

Paciente 13: Eu acho que trouxe (conseqüência) porque eu perdi a força na mão e a força de sustentação.

Paciente 3: Ah, hoje em dia eu estou com uns problemas de depressão, depois do acidente eu não fiquei boa.

Paciente 21: Principalmente a saúde, vamos bem dizer né? Perdi a saúde com a queimadura.(...) É, me deu uma doença no sangue, uma tal de sífilis, sabe né?

A categoria mudança de valores refere-se a descrições sobre alterações na relação com familiares e amigos, a valorização da vida e ao apego à religiosidade. Os participantes relataram que passaram a valorizar mais a vida, pois se sentiram mais próximos de seus familiares e amigos, receberam uma maior atenção e também relataram um maior apego à religião, devido à experiência vivenciada.

Paciente 10: Mais sobre família mesmo, mais união assim com a família, a gente não era muito, né mais unido assim né, depois disso aí parece que a gente viu, que muitas pessoas que achava que não gostava da gente, que a gente não tinha, sei lá que não se interessava, a gente viu que depois que acontece as coisas não é aquilo que a gente achava que era, muda bem a vida da gente, a minha mudou nesse termo assim.

Paciente 29: $E$ eu agradeci por ter queimado só um pouquinho. Acho que eu vou dar mais valor na vida agora.

Em relação às mudanças no estilo de vida, os aspectos agrupados nesta categoria foram: tomar mais cuidado no dia a dia para evitar acidentes, ter aprendido coisas novas e abandonado vícios. Nesse sentido, alguns pacientes relataram que deixaram de beber e de fumar.

Paciente 27: Ah, a gente pensa de outro jeito, a vida que você fazia né? Assim, você tinha um jeito de pensar né, aí você vê essas coisas, ficava pensando diferente o que podia acontecer, prestar mais atenção nas coisas, né? Mudou meu modo de vida.

Paciente 25: Aprendi algumas coisas, que a gente estando assim, a gente não pode desanimar, quando mais você se anima, mais te ajuda a melhorar a situação (...).

Mudanças no papel social e nas relações interpessoais foram citadas por 3 participantes. Nessa categoria, estão 
incluídos: o afastamento do serviço e a percepção de estar sendo desprezado por pessoas próximas em razão de marcas e mudanças corporais.

Paciente 11: Olha, primeiramente eu estou afastada do serviço, não tem previsão de quando eu vou voltar a trabalhar, não tem como trabalhar (...)

Paciente 12: É, eu me senti mais feia, né, sem sair de casa, não saio assim mais (...) Ah, você fica como se tivesse sendo desprezada, entendeu?

\section{DISCUSSÃO}

Estudos que abordem a vivência do indivíduo que sofre queimaduras, acidentais ou não, são escassos em nosso meio. Assim, este estudo buscou contribuir com o tema, identificando as situações vivenciadas por pacientes queimados durante o período de internação hospitalar.

Neste estudo, observou-se que a dor, considerada pelos pacientes como uma situação significante, foi relacionada por eles aos procedimentos de banho, curativo e cirurgia. Embora tenha analisado as dimensões do cuidado a partir da perspectiva dos profissionais nessa mesma Unidade de Queimados,outro estudo ${ }^{(18)}$ encontrou resultados semelhantes. A expectativa de submeter-se a procedimentos e, conseqüentemente, sentir dor, gera ansiedade. Pacientes queimados apresentam elevados níveis de ansiedade relacionados ao tratamento e aos seus resultados. Aumentando a ansiedade, a percepção de dor também aumenta e essa percepção pode elevar mais ainda o nível de ansiedade e, com isso, forma-se um ciclo dor-ansiedade ${ }^{(19)}$. O ciclo dor-ansiedade é manifestado por irritabilidade, inquietudes, queixas, solidão e choro ${ }^{(13)}$. Entretanto, no banho e no curativo, pode haver uma relação de dor e alívio, pois os pacientes têm a perspectiva da cicatrização da ferida ou dos resultados da cirurgia, o que pode propiciar-lhe uma expectativa de melhora e de possibilidade de alta hospitalar ${ }^{(13)}$.

A dor pode ser relacionada às dificuldades no tratamento e complicações em razão de situações tais como: depressão, perda do apetite, distúrbios do padrão do sono e ansiedade. É importante entender a dor, porque essa pode dificultar a recuperação; entretanto, há poucos estudos que evidenciam a relação entre dor e sofrimento do paciente e complicações $^{(1)}$.

Além da dor, este estudo também mostra a importância atribuída pelo paciente à presença do apoio e do encorajamento da família e da equipe, considerados como fundamentais durante o período de internação. Possivelmente, a importância do apoio da família e da equipe está relacionada ao fato de a queimadura ser uma experiência nova, estressante e dolorosa, ao grande período pelo qual o paciente passa longe de casa, de seus amigos e de sua vida cotidiana e, ainda, ao fato de estar em um ambiente de uma unidade especializada que é totalmente novo para ele. Tanto os pacientes que consideraram não ter apoio suficiente da equipe ou de seus familiares ou de ambos quanto os que relataram que tiveram esse apoio consideraram esse aspecto como relevante.

$\mathrm{Na}$ fase de ressuscitação, os pacientes, assim como as famílias, passam por problemas de adaptação e estão preocupados com a sobrevivência ${ }^{(2-3)}$. Nessa fase, as manifestações muitas vezes são de ansiedade grave ${ }^{(3)}$. Posteriormente, a presença da família pode aliviar os sintomas de ansiedade e de agitação; entretanto, se a família mostrar altos níveis de estresse e ansiedade, os pacientes também serão influenciados por essas situações ${ }^{(2)}$. Há estudos ${ }^{(20-21)}$ que mostram que o apoio da família, durante o período de internação, é muito importante e contribui para o sucesso da reabilitação. Em estudo ${ }^{(13)}$ realizado na mesma Unidade onde esta investigação foi desenvolvida, observou-se que a relação dos pacientes com a família e pessoas significativas gerava sentimentos de ansiedade e saudade, independentemente de a relação ser boa ou não.

Conjuntamente, a equipe também pode ajudar no processo de internação do paciente queimado, não somente quando realiza técnicas e procedimentos, mas também por meio de aproximações sucessivas, planejadas, independentes da solicitação do paciente, mostrando-se disponível e sensível frente à situação e explicando claramente os procedimentos que serão realizados, buscando aliviar a ansiedade e estabelecer um bom vínculo com o paciente. A educação continuada, visando ao preparo da equipe para apoiar a família e o paciente, pode facilitar a adaptação psicológica. A organização de grupos de apoio para familiares é uma das formas que pode ser utilizada para facilitar a adaptação. Esses grupos podem ser organizados entre familiares de diferentes pacientes e a equipe multiprofissional, propiciando a socialização entre eles ${ }^{(2)}$ e com pacientes e equipe, promovendo a discussão de seus problemas ${ }^{(12)}$. Quando o paciente conta com o apoio da família, qualquer tratamento psicoterápico ao qual ele venha a submeter-se é mais efetivo $^{(2-3)}$. Em outro estudo ${ }^{(22)}$ evidenciou-se que, repetidamente, os pacientes expressaram gratidão pelo apoio recebido da família durante e depois do período de hospitalização, o que também foi observado nos relatos dos participantes em nosso estudo.

Entretanto, a relação do paciente com a família pode também ser afetada após a experiência traumática da queimadura. Além das modificações físicas e emocionais que se observam, passar por uma experiência de queimadura altera profundamente a relação interpessoal e a convivência com o mundo social, em função da ansiedade e de medos que são projetados pelos pacientes e familiares no que diz respeito à manutenção da capacidade produtiva. Os indivíduos que sofrem queimaduras temem, particularmente, os sentimentos de repulsa e o medo de ser privado do afeto 
daqueles que o cercam. Por isso, são freqüentes as manifestações de insegurança e sentimentos de amor e ódio em relação à família e às pessoas próximas ${ }^{(13)}$.

Os participantes deste estudo relataram ainda sentimentos e comportamentos que expressam o sofrimento durante o período de internação. As manifestações de sofrimento relatadas foram: choro, tristeza e revolta por estar internado e pela própria condição, o remorso, a solidão e a saudade de casa, dos familiares e de pessoas próximas. É importante ressaltar que o sofrimento relatado pelos pacientes queimados está associado a situações que foram consideradas relevantes como receber o apoio da família, conhecer a situação de outros pacientes e sentir dor.

A complexidade do sofrimento pode ter componentes físicos, cognitivos, afetivos, sociais e espirituais. O sofrimento pode estar acompanhado por manifestações físicas e afetivas como o choro e a expressão de dor física, expressões de angústia mental, sentimentos de medo ou culpa ${ }^{(23)}$, isolamento frente a outras pessoas e questionamento sobre a morte e sobre a crença religiosa. Além disso, o sofrimento envolve grande senso de perda da integridade pessoal, da autonomia ou do controle total de sua situação ou da vida ${ }^{(23)}$. Cada paciente pode ter uma reação diferente que dependerá de fatores individuais. Alguns desses fatores são: estado emocional prévio, personalidade, tipo de resposta a situações novas, a condição psiquiátrica e a adaptação psicossocial prévias, a influência das características da queimadura como a sua extensão, gravidade, áreas atingidas e a presença de dor ${ }^{(5)}$, o tipo e a causa da queimadura.

O profissional de enfermagem tem um papel importante na reabilitação do paciente queimado. Intervenções de enfermagem durante essa fase devem incluir atividades destinadas a reduzir a ansiedade e minimizar o sofrimento frente à hospitalização, ao ambiente estranho, aos distúrbios de padrão do sono, à administração de medicamentos e à dor ${ }^{(3)}$. Cabe à equipe de enfermagem propiciar calma, esperança e apoio.

A convivência com outras pessoas queimadas foi considerada como uma experiência nova e significante. Essa experiência foi relatada por alguns pacientes como importante, pois se sentiam sensibilizados ao ver outras pessoas em piores condições e, para alguns, facilitava a aceitação de sua condição. É importante ressaltar que, na literatura, não encontramos estudos que relacionassem essa situação de ver outras pessoas queimadas com o sentimento de conforto expressado pelos pacientes.

Para os participantes, a experiência de sofrer uma queimadura e passar pelo processo de internação trouxe algumas conseqüências como mudanças de valores na vida, no estilo de vida, na saúde e no papel social e nas relações interpessoais.
Limitações físicas (perder a força no braço) e alterações emocionais (depressão) foram conseqüências relatadas pelos participantes e agrupadas como mudanças no estado de saúde. As alterações na estrutura e função que podem provocar limitações físicas, constituem conseqüências comuns das queimaduras. Essas alterações, frequentemente, provocam problemas como a depressão que foi relatada por participantes deste estudo. Entretanto, é importante considerar que há uma grande incidência de desajustes psicológicos entre pessoas que estão internadas em unidades de queima$\operatorname{dos}^{(1)}$ e estima-se também que há uma incidência maior de distúrbios psiquiátricos prévios ao acidente nessas unidades comparativamente à população em geral $^{(2)}$. Pacientes com diagnósticos psiquiátricos prévios tendem a ficar mais tempo na Unidade de Queimados e a desenvolver complicações psiquiátricas sérias depois da queimadura. Uma vez hospitalizados, esses pacientes recorrem a modos disfuncionais de adaptação como regressão, depressão e falta de controle sobre agressividade ${ }^{(1)}$.

Nesse contexto, podemos enfatizar o papel da equipe de saúde, que deve estar preparada para identificar mudanças de comportamento, fornecer apoio e, depois da alta hospitalar, proporcionar um seguimento na residência, não somente para aqueles que apresentam algum distúrbio psicopatológico durante a internação, mas também para aqueles que possam, posteriormente, apresentar problemas dessa natureza.

Alguns participantes relataram que houve mudanças no papel social e no relacionamento interpessoal. Essas mudanças foram: ser afastado do serviço devido a uma limitação física e percepção de estar sendo desprezado por pessoas próximas devido às marcas da queimadura. A alteração de uma parte do corpo, mediante procedimentos cirúrgicos ou desfiguramento, como ocorre no caso de queimaduras, necessita de atenção especial, porque essas mudanças são freqüentemente abruptas, com implicações na aparência e também na função ${ }^{(24)}$ e tem implicações no relacionamento interpessoal.

\section{CONCLUSÕES}

As situações relatadas como significantes pelos pacientes que sofreram queimaduras foram: ter que se submeter a procedimentos e sentir dor; receber ou não o apoio da família e da equipe; viver uma nova experiência e conhecer a situação de outras pessoas queimadas. Diante dessas situações, os pacientes relataram os seguintes sentimentos/comportamentos: sofrimento; ansiedade e medo e conforto de ver outras pessoas em piores condições. Como conseqüência da vivência da experiência da queimadura, os pacientes relataram: mudanças na saúde, mudanças de valores, mudança de estilo de vida e mudanças no papel social e nas relações interpessoais e alguns não identificaram conseqüências. 
Nos relatos dos pacientes observou-se que a experiência de vivenciar uma queimadura pode trazer mudanças significativas nos aspectos físico e psicológico durante o período de internação e após a alta hospitalar.

A equipe que atua em Unidades de Queimados deve estar preparada para identificar situações que podem ser estressantes para o paciente, não somente durante o perío- do de internação, mas também após a alta hospitalar. Consideramos importante a realização de estudos que busquem avaliar o preparo da equipe, que atua em unidades de queimados, para assistir aos pacientes e famílias, enfocando não somente a queimadura do ponto de vista biológico, mas também a experiência de viver essa situação na perspectiva das pessoas envolvidas: pacientes e familiares.

\section{REFERÊNCIAS}

1. Patterson DR, Everett JJ, Bonbardier CH, Questad KA, Lee VK, Marvin JA. Psychological effects of severe burn injuries Psychol Bull. 1993;113(2):362-78.

2. Adcock RJ, Boeve SA, Patterson DR. Psychological and emotional recovery. In: Carrougher, GJ. Burn care and therapy Saint Louis: Mosby; 1998. p. 329-49.

3. Summers TM. Psychosocial support of the burned patient. Crit Care Nurs Clin North Am. 1991;3(2):237-44.

4. Andreasen NJC, Noyes R, Hartford CE, Broldland G, Proctor S. Management of emotional reactions in seriously burned adults. N Engl J Med. 1972;286(2):65-9.

5. Franulic A, Gonzalez X, Trucco M, Vallejos F. Emotional and psychosocial factors in burn patients during hospitalization. Burns. 1996;22(8):618-22.

6. Weinberg K, Birdsall C, Vail D, Marano Ma, Petrone SJ, Mansour EH. Pain and anxiety with burn dressing changes: patient selfreport. J Burn Care Rehabil. 2000; 21(2):155-61.

7. Aaron LA, Patterson DR, Finch CP, Carrouguer GJ, Heimbach DM. The utility of a burn specific measure of pain anxiety to prospectively predict pain and function: a comparative analysis. Burns. 2001;27(4):329-34.

8. Ehde DM, Patterson DR, Wiechman SA, Wilson LG. Posttraumatic stress and distress following acute burn injury. Burns. 1999;25(7):587-92.

9. Choiniere M, Melzack J, Girard N, Paquin MJ. The pain of burns: characteristics and correlates. J Trauma. 1989; 29(11): $1531-9$.

10. Byers JF, Bridges S, Kijek J, LaBorde P. Burns patients pain and anxiety experiences. J Burn Care Rehabil. 2001;22(2): $144-9$

11. Taal LA, Faber AW. Post-traumatic stress, pain and anxiety in adult burns victims. Burns. 1997;23(7/8):545-9.

12. Gilboa D. Long-term psychosocial adjustment after burn injury. Burns. 2001;27(4):335-41.

13. Sherer ZAP, Percepções e significados atribuídos pelos pacientes à vivência da queimadura: a importância do processo interativo paciente enfermeiro de saúde mental [dissertação]. Ribeirão Preto: Escola de Enfermagem de Ribeirão Preto, Universidade de São Paulo; 1995.
14. Chianca TCM. Uma visão sistêmica do transporte do paciente cirúrgico [dissertação]. Ribeirão Preto: Escola de Enfermagem de Ribeirão Preto, Universidade de São Paulo; 1992.

15. Nogueira MS. Incidentes críticos na passagem de plantão [dissertação]. Ribeirão Preto: Escola de Enfermagem de Ribeirão Preto, Universidade de São Paulo; 1988.

16. Ravagnani MJC. Vivências de mulheres submetidas à cesiomoldagem [dissertação]. Ribeirão Preto: Escola de Enfermagem de Ribeirão Preto, Universidade de São Paulo; 1991.

17. Flanagan JC. A técnica do incidente crítico. Arq Bras Psiq Aplicada. 1973;25(2):99-141.

18. Costa ECFB, Rossi LA. As dimensões do cuidado em uma unidade de queimados: um estudo etnográfico. Rev Esc Enferm USP. 2003;37(3):72-81.

19. Marvin JA. Management of pain and anxiety. In: Carrouger, GJ. Burn care and therapy. Saint Louis: Mosby; 1998. p. $167-80$.

20. Davidson TN, Bowden ML, Tholen D, James MH, Feller I. Social support and post burn adjustment. Arch Phys Med Rehabil. 1981;62(2):274-8.

21. Barnes A, Budd L. Family-centred burn care. Can Nurse. 1999;95(6):24-7.

22. Andreasen NJ, Norris AS, Hartford CE. Incidence of long-term psychiatric complications in severely burned adults. Ann Surg. 1971;174(5):785-93.

23. Rodgers BL, Cowles KV. A conceptual foundation for human suffering in nursing care and research. J Adv Nurs. 1997;25 (5):1048-53.

24. Bergamasco EC, Rossi LA, Amâncio ACG, Carvalho EC. Body image of patients with burns sequellae: evaluation through the critical incident technique. Burns. 2002;2(1)8:47-52. 